\title{
Exposure of the eye lens and brain for interventional cardiology staff
}

\author{
Joanna Kidoń ${ }^{1}$, Kinga Polaczek-Grelik², Przemysław Żurek ${ }^{3}$, Wojciech Wojakowski ${ }^{4}$, Andrzej Ochala ${ }^{1}$ \\ ${ }^{1}$ Invasive Cardiology and Electrocardiology Department, Medical University of Silesia, Katowice, Poland \\ ${ }^{2}$ Prof. K. Gibiński Memorial University Clinical Centre, Medical University of Silesia, Katowice, Poland \\ ${ }^{3} 2^{\text {nd }}$ Department of Cardiology, Upper Silesian Medical Center, Katowice, Poland \\ ${ }^{4} 3^{\text {rd }}$ Department of Cardiology, School of Medicine, Medical University of Silesia, Katowice, Poland
}

Adv Interv Cardiol 2021; 17, 3 (65): 298-304

DOI: https://doi.org/10.5114/aic.2021.109576

\section{A bstract}

Introduction: Occupational exposure to ionizing radiation for people working with an X-ray treatment unit is one of the highest in medicine. The epidemiological data analyzed by the International Commission on Radiological Protection (ICRP) indicate that the dose threshold for tissues located in the eye lens is or may be lower than previously thought. The new ICRP recommendations reduce the currently used threshold 7.5 times to the limit of $20 \mathrm{mSv}$ per year.

Aim: To carry out measurements of equivalent doses for the lenses and scalps of cardiology interventional staff to determine the actual exposure.

Material and methods: Personnel performing interventional cardiology procedures participated in the measurements. The measurements were performed using thermoluminescence dosimetry in two measurement periods. The operational quantities used in individual dosimetry were determined (dose equivalent for the scalp, dose equivalent for the eye lens). In both measurement periods, 69 operators and 12 nurses took part.

Results: The maximum value of eye doses for cardiologists was $18.80 \mathrm{mSv}$ per year, with a mean of $9.83 \pm 6.47 \mathrm{mSv} /$ year (for all cases), $5.70 \pm 4.26 \mathrm{mSv} /$ year (with safety glasses/headgear), $13.14 \pm 6.28 \mathrm{mSv} /$ year (without safety glasses/headgear), and 6.28 $\pm 1.76 \mathrm{mSv}$ per year for the nurses. The values of brain doses fluctuate around $1 \mathrm{mSv}$ per quarter.

Conclusions: Dose equivalents for the lenses of the eyes obtained by cardiologists may be close to or exceed the current dose limits.

Key words: interventional cardiology, exposure to the lenses, exposure to the brain.

Su m m a ry

The research concerned the topic of reducing the limit of equivalent doses for lenses and the assessment of brain exposure for personnel performing interventional cardiology procedures. The new International Commission on Radiological Protection (ICRP) recommendations significantly reduce the currently used dose threshold for lenses, and there have also been reports of an increased risk of operators developing brain tumors as a result of chronic occupational exposure to ionizing radiation. We found that dose equivalents for the lenses of the eyes obtained by cardiologists may be close to or exceed the current dose limits. The values of brain doses fluctuate around $1 \mathrm{mSv}$ per quarter. Our article aims to increase the staff awareness of radiation protection, with particular emphasis on the need for proper use of anti-radiation shields and dosimetry systems in routine practice.

\section{Introduction}

Medical procedures performed under the fluoroscopy condition are characterized by widely variable doses of ionizing radiation per single procedure [1]. This gener- ates the possibility of both patients and staff receiving high doses of ionizing radiation. Occupational exposure to ionizing radiation for people working with an X-ray treatment unit is, apart from work in nuclear medicine, one of the highest in medicine [2]. The increasing num-

\section{Corresponding author:}

Joanna Kidoń PhD, Invasive Cardiology and Electrocardiology Department, Medical University of Silesia, Katowice, Poland, phone: +48 601438 722, e-mail: joanna.kidon@sum.edu.pl

Received: 3.03.2021, accepted: 12.08 .2021$. 
ber of interventional procedures using X-ray units and the degree of complexity of these procedures increases the exposure of medical personnel and patients to ionizing radiation [3].

The latest epidemiological data analyzed by the International Commission on Radiological Protection (ICRP) indicate that there are certain types of tissues, especially with the relatively late manifestation of the adverse effects of ionizing radiation, for which the dose threshold is lower than previously thought. This type of tissue includes the eye lens [2]. Without adequate protection (safety glasses, headgear, overhead shields), the dose absorbed by the lens may exceed the ICRP threshold. Cataracts can develop over 25 years after exposure. Early changes were observed in operators who worked for many years in the interventional $X$-ray unit environment [1]. The latest research under the patronage of the IAEA and RELID (Retrospective Evaluation of Lens Injuries and Dose) indicates a significant increase in the occurrence of lens opacities caused by ionizing radiation (about $40-50 \%$ in interventional radiologists, $20-40 \%$ in electroradiology technicians and nurses) and incidents of posterior subcapsular cataracts in the event of occupational exposure of personnel working with the X-ray treatment units. In some cases, lifetime doses are estimated at a level of several Gy. The current dose threshold for the occurrence of deterministic effects for the lenses is 0.5 Gy [4], with the time of appearance of the effects being at least 1 year [1]. However, the ICRP emphasizes that the proper use of anti-radiation shields significantly reduces the risk of cataracts [2]. Scientific reports suggest a significant reduction in the dose threshold for the appearance of deterministic effects for the eye lens, which is also a result of chronic occupational exposure to ionizing radiation. With these observations in mind, the new ICRP recommendations reduce the currently used threshold 7.5 times to a limit of $20 \mathrm{mSv} /$ year. The limits of ionizing radiation doses are set in such a way as to prevent the occurrence of deterministic effects, and the probability of stochastic effects is set at a very low, acceptable level $(0.6 \%$ for genetic effects and $4 \%$ for cancer) [5]. Furthermore, Article 41 of the Euroatom Directive 59/2013 obliges Member States to systematically control the exposure of category A workers and, additionally, to implement an appropriate monitoring system in the event of significant exposure of the eye lens or limbs [6].

There have been reports of an increased risk of operators developing brain tumors as a result of chronic occupational exposure to ionizing radiation $[7,8]$. However, according to ICRP report number 139 , extensive epidemiological studies conducted in 2016-2017 did not confirm these observations [2]. Over 43,000 people participated in the research, i.e. 45,000 interventional radiologists and - as a reference group - 60,000 psychiatrists. A group of interventional radiologists showed a reduced risk of developing brain cancer (brain tumors, or primary malignancies of the brain). Similarly, in a long-term study of a group of over 100,000 American electroradiology technicians who stated that they work with X-ray surgical units, no relationship between occupational exposure to ionizing radiation and mortality caused by malignant intracranial tumors was found [2].

\section{Aim}

In our study, we measured the equivalent doses which were taken from cardiology interventional staff with particular emphasis on eye lenses and the scalp. The project also aimed to increase the awareness of protection against radiation among staff, with particular emphasis on the need for proper use of anti-radiation shields and dosimetry systems in routine practice.

\section{Material and methods}

The research project was approved by the Bioethical Committee of the Medical University of Silesia in Katowice, decision number KNW/0022/KB1/68/18 of September 25, 2018.

The research group consisted of personnel performing interventional cardiology procedures. The measurements were performed using thermoluminescence dosimetry in two measurement periods (3 months each). During the measurements, the operational quantities used in individual dosimetry were determined $(\mathrm{Hp}(0.07)$ - dose equivalent for the scalp, $\mathrm{Hp}(3)$ - dose equivalent for the eye lens). In the first measurement period (from August to November 2018) 35 operators participated, and in the second (March-June 2019) a further 34 operators and 12 nurses who assisted during cardiological procedures took part. Dosimeters were placed on the left side of the heads of staff members (Figure 1).

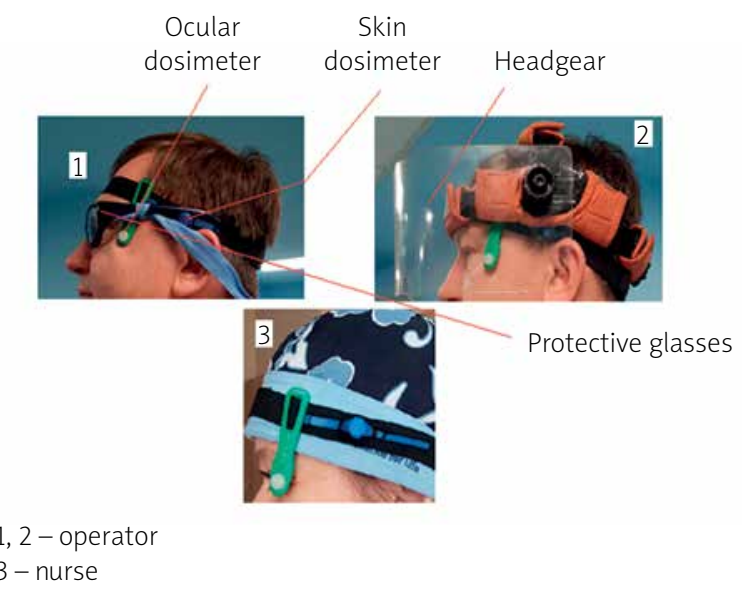

Figure 1. Measurement system of TLD dosimeters in the head area of staff, ocular dosimeter - measurement of the dose equivalent to the lens of the eye (Hp (3)), dermal dose meter - dose equivalent to the scalp (Hp (0.07)) 


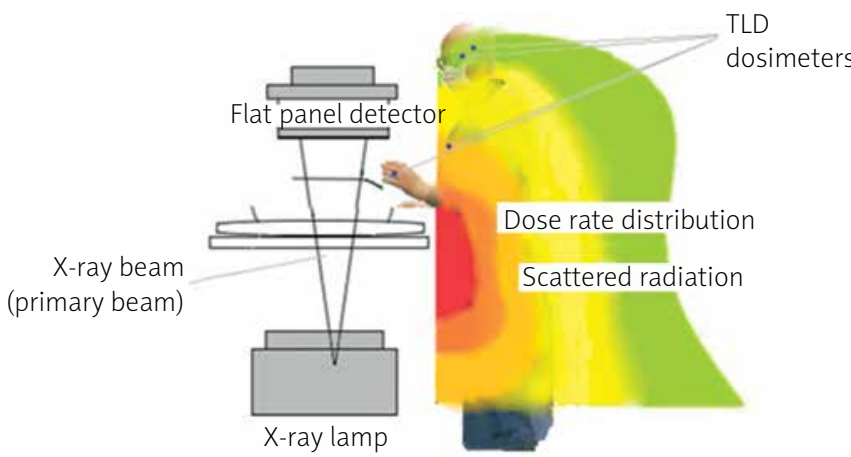

Figure 2. Irradiation scheme, distribution of the scattered radiation dose rate and the placement of dosimeters

All dosimeters were used in accordance with the conditions specified in their suitability certificates. The calibration and reading process was carried out by an accredited laboratory in accordance with its own methodology (expanded uncertainty $(k=2) \pm 10 \%)$. The thermoluminescent dosimeter (TLD) measuring dose range was from $0.1 \mathrm{mSv}$ to $1.0 \mathrm{~Sv}$ for ocular and skin dosimeters.

Apart from the location of dosimeters, Figure 1 shows the use of anti-radiation shields in the form of protective glasses, headgear (physicians), and the lack of personal shields around the head (nursing staff). In all cases, the glasses had a lead equivalent of 0.75 and the headgear had an equivalent of 0.1 . The dosimeters were placed either under the cover or outside it (when the cover was not used or its shape made it impossible to cover the dosimeter) according to the practices used during routine work. Background measurements in the operating room were performed using a set of dosimeters $\mathrm{Hp}(0.07)$ $+\mathrm{Hp}(3)$ in the first measurement period and using the RK-100-2 environmental radiometer in the second measurement period, calibrated in the N-100 X-ray beam by an accredited laboratory. The measured background was below $0.1 \mathrm{mSv}$ and below $0.24 \mu \mathrm{Sv} / \mathrm{h}$, respectively.

Figure 2 shows the scattered radiation dose rate distribution from the operator's side, shown on a color scale (red corresponds to the highest value, and green to the lowest) based on the previously published method [9] as well as the placement of dosimeters.

Cardiovascular interventions were performed using three angiographs (Infinix Vf-I, Canon (2017), Artis zee flor, Siemens (2010), and Allura Xper FD20, Philips (2011)). Those X-ray units have a digital image detector (flat-panel detector - FPD), a fixed isocenter, and work in the pulse or continuous fluoroscopy mode. They also have a system for monitoring the dose received by the patient. The abovementioned $\mathrm{X}$-ray units were equipped with a ceiling protective shield with a lead equivalent of 0.5, except for the first unit, where it was 1.1. Our X-ray units are subject to systematic quality control. All param- eters measured during the tests met the test acceptance criteria (specified in the Polish legal requirements).

In order to determine the degree of radiation absorption by the scalp and skull bones, the following coefficient was used:

$f=\left(\frac{\mu_{\text {en }}}{\varrho}\right)_{\text {air }}^{\text {bone }}$ - the quotient of mass energy-absorption $\approx 4.75$ [10].

The detailed analysis of the results included people whose $\mathrm{Hp}(3)$ reading was above $1 \mathrm{mSv}$ per quarter, as well as people whose dosimeter readings were above the sensitivity threshold and who reported $100 \%$ frequency of wearing TLD dosimeters in a given measurement period. The analysis also took into account parameters read from the dosimetric report generated by the X-ray units of all treatments/examinations (total kerma area product - KAP, and total kerma in reference point $-\mathrm{K}_{\text {air,ef }}$ ) in given measurement periods, the duration of fluoroscopy and the number of acquisition images, as well as the number of medical procedures. The total number of analyzed medical procedures in both measurement periods was 2519 .

Table I includes data on the examinations/treatments carried out in individual measurement periods (dosimetric parameters, number of procedures, procedures with the highest frequency, the most frequently used X-ray unit, approach path to the examined organ). This table gives data for the staff with the highest dose equivalent per lens value measured and for the entire group of staff (mean value, standard deviation and median).

The reading above the background for any of the dosimeters of the $\mathrm{Hp}(3)+\mathrm{Hp}(0.07)$ system was recorded for 25 and 28 people for the first and second periods of measurement respectively. According to the criterion adopted in the methodology, five (during the first period) and eight (during the second period) operators, as well as nine nurses (during the second period) were included in the further analysis. The annual exposure was performed based on estimated values from quarterly measurements.

The degree of dependence of the variables was determined by checking their correlations. Tests based on Spearman's rank correlation coefficient (used for variables specified on the ordinal scale, and also for quantitative features for a small number of observations) were used.

\section{Results}

The maximum and mean values of the dose equivalent for the eye lens and brain are presented in Table II. The high values of dose equivalent $\mathrm{Hp}(3)$ per year for cardiologists are noteworthy.

The maximum obtained $\mathrm{Hp}(3)$ value of $4.7 \mathrm{mSv}$ per quarter (operator) was related to the case in which the dosimeter was located outside the protective glasses in the shape of sports glasses. In the next measurement period, this doctor used protective headgear for twothirds of this period. Significant reductions in the dose 
Table I. Radiological procedures - summary of dosimetric parameters and characteristics of the procedures performed

\begin{tabular}{|c|c|c|c|c|c|c|c|c|}
\hline \multirow[t]{3}{*}{ Personnel } & \multicolumn{4}{|c|}{ Dosimetric parameters in the measurement period } & \multicolumn{4}{|c|}{ Procedures } \\
\hline & \multirow{2}{*}{$\begin{array}{c}\text { Total } K_{\text {air,ref }} \\
{[G y]}\end{array}$} & \multirow{2}{*}{$\begin{array}{l}\text { Total KAP } \\
{\left[\mathrm{mGy}^{*} \mathrm{~m}^{2}\right]}\end{array}$} & \multirow{2}{*}{$\begin{array}{c}\text { Total fluoro } \\
\text { time }^{\star *}[\mathrm{~h}]\end{array}$} & \multirow{2}{*}{$\begin{array}{c}\text { No. of ac- } \\
\text { quisitions }{ }^{* *}\end{array}$} & \multirow{2}{*}{$\begin{array}{c}\text { No. of } \\
\text { procedures } \\
\text { performed } \\
\text { in two } \\
\text { periods }\end{array}$} & \multicolumn{3}{|c|}{ Highest frequency (\% of total) } \\
\hline & & & & & & Procedures & $\begin{array}{l}\text { Artery } \\
\text { access }\end{array}$ & X-ray unit \\
\hline \multicolumn{9}{|l|}{ Cardiologist: } \\
\hline $\begin{array}{l}\text { Maximum } \\
\text { value for lens }\end{array}$ & 118.0 & 643.7 & 16.1 & 1614 & 239 & $\begin{array}{c}d(57.4 \%) \\
d-t(36.8 \%)\end{array}$ & $p(64.0 \%)$ & $\mathrm{T}(82.0 \%)$ \\
\hline $\begin{array}{l}\text { Throughout } \\
\text { the group } \\
\text { Mean } \pm \text { SD } \\
\text { (median) }\end{array}$ & $\begin{array}{l}42.2 \pm 13.1 \\
(44.0)\end{array}$ & $\begin{array}{c}282.1 \pm 85.0 \\
(299.3)\end{array}$ & $\begin{array}{c}17.9 \pm 4.1 \\
(16.1)\end{array}$ & $\begin{array}{l}1551 \pm 597 \\
(1339)\end{array}$ & $\begin{array}{c}110.3 \pm 17.4 \\
(114.0)\end{array}$ & $\begin{array}{c}d(55.5 \pm 8.1 \% \\
(56.5)) \\
d-t(37.7 \\
\pm 4.7(38.9))\end{array}$ & $\begin{array}{c}p(70.7 \\
\pm 10.3 \% \\
(67.5))\end{array}$ & $\begin{array}{c}\text { T (66.5 } \\
\pm 11.8 \% \\
(61.7))\end{array}$ \\
\hline \multicolumn{9}{|l|}{ Nurse: } \\
\hline $\begin{array}{l}\text { Maximum } \\
\text { value for lens }\end{array}$ & 47.7 & 312.4 & 18.3 & 1636 & 137 & $\begin{array}{c}d(51.1 \%) \\
d-t(37.2 \%)\end{array}$ & $p(63.5 \%)$ & $\mathrm{T}(64.2 \%)$ \\
\hline $\begin{array}{l}\text { Throughout } \\
\text { the group } \\
\text { Mean } \pm \mathrm{SD} \\
\text { (median) }\end{array}$ & $\begin{array}{c}37.8 \pm 9.4 \\
(40.8)\end{array}$ & $\begin{array}{c}260.9 \pm 57.9 \\
(266.3)\end{array}$ & $\begin{array}{c}17.6 \pm 3.4 \\
(18.0)\end{array}$ & $\begin{array}{c}1510 \pm 292 \\
(1580)\end{array}$ & $\begin{array}{c}130.4 \pm 20.5 \\
(126.0)\end{array}$ & $\begin{array}{c}d(55.4 \\
\pm 4.7 \%(55.6)) \\
d-t(37.7 \\
\pm 4.7(38.9))\end{array}$ & $\begin{array}{c}p(69.0 \\
\pm 6.6 \%(72.6))\end{array}$ & $\begin{array}{c}\mathrm{T}(66.9 \\
\pm 5.1 \%(66.9))\end{array}$ \\
\hline
\end{tabular}

$K_{\text {airref }}$ - kerma in reference point, KAP-kerma area product, $d$-diagnostic procedure, $d$ - $t$-diagnostic and therapeutic procedure, $p$-radial approach path, $T$-angiograph Infinix Vf-I (Canon, 2017), ${ }^{* *}$ only recorded in the second measurement period, Total fluoro time - total fluoroscopic time.

Table II. Values of the dose equivalent for the eye lens and brain

\begin{tabular}{|c|c|c|c|}
\hline Value & Personnel & Dose equivalent for eye $\mathrm{Hp}(3)$ & Brain doses $(\mathrm{Hp}(0.07) / f)$ \\
\hline \multirow[t]{2}{*}{ Maximum } & Cardiologists & $\begin{array}{c}18.80 \mathrm{mSv} / \text { year } \\
4.70 \mathrm{mSv}\left(1^{\text {st }} \text { quarter }\right)^{1} \\
2.95 \mathrm{mSv}\left(2^{\text {nd }} \text { quarter }\right)^{2}\end{array}$ & $\begin{array}{c}4.32 \mathrm{mSv} / \text { year } \\
1.07 \mathrm{mSv}\left(1^{\text {st }} \text { quarter }\right)^{1} \\
0.62 \mathrm{mSv}\left(2^{\text {nd }} \text { quarter }\right)^{2}\end{array}$ \\
\hline & Nurses & $9.88 \mathrm{mSv} /$ year & $2.08 \mathrm{mSv} /$ year \\
\hline \multirow[t]{2}{*}{ Mean \pm SD } & Cardiologists & $\begin{array}{l}\text { For all cases*: } 9.83 \pm 6.47 \mathrm{mSv} / \text { year: } \\
\text { With safety glasses/headgear: } \\
\quad 5.70 \pm 4.26 \mathrm{mSv} / \text { year } \\
\text { Without safety glasses/headgear: } \\
\quad 13.14 \pm 6.28 \mathrm{mSv} / \text { year }\end{array}$ & $\begin{array}{l}\text { For all cases*: } \\
2.39 \pm 1.41 \mathrm{mSv} / \text { year }\end{array}$ \\
\hline & Nurses & $6.28 \pm 1.76 \mathrm{mSv} /$ year & $1.49 \pm 0.37 \mathrm{mSv} /$ year \\
\hline \multirow{2}{*}{$\begin{array}{l}\text { Quarterly read- } \\
\text { ings (mean } \\
\pm \text { SD) }\end{array}$} & Cardiologists & $2.51 \pm 1.58 \mathrm{mSv}(\max =4.7)$ & $2.75 \pm 1.77 \mathrm{mSv}(\max =5.12)$ \\
\hline & Nurses & $1.57 \pm 0.44 \mathrm{mSv}(\max =2.31)$ & $1.77 \pm 0.44 \mathrm{mSv}(\max =2.47)$ \\
\hline \multirow[t]{2}{*}{$\begin{array}{l}\text { For a single } \\
\text { procedure }\end{array}$} & Cardiologists & $\begin{array}{l}\text { For all cases* }- \text { mean: } 23.50 \mu \mathrm{Sv} \text {, } \\
\text { median: } 24.79 \mu \mathrm{Sv}(\mathrm{min}=5.25, \mathrm{max}=43.70) \\
\text { For a } 100 \% \text { frequency of wearing eye dosimeters } \\
- \text { mean: } 25.44 \mu \mathrm{Sv} \text {, median: } 30.27 \mu \mathrm{Sv} \\
(\min =5.25, \max =43.70)\end{array}$ & $\begin{array}{l}\text { For a } 100 \% \text { frequency of wearing eye dosimeters } \\
\qquad- \text { mean: } 6.34 \mu \mathrm{Sv}\end{array}$ \\
\hline & Nurses & $\begin{array}{c}\text { Mean: } 13.21 \mu S v, \text { median: } 13.27 \mu S v(\min =9.25 \\
\max =16.86 \mu S v)\end{array}$ & $3.06 \mu \mathrm{Sv}$ \\
\hline
\end{tabular}

*Different frequency of wearing TLD dosimeters declared, SD - standard deviation, 1 - protective glasses (0.75 mm eg. Pb), dosimeter Hp (3) was outside the glasses (number of procedures performed in period - 120), 2 - for $1 / 3$ of the measurement period safety glasses were used ( $0.75 \mathrm{~mm}$ eg. Pb), dosimeter $\mathrm{Hp}$ (3) was outside the glasses, for 2/3 of the measurement period headgear was used $(0.1 \mathrm{~mm}$ eq. Pb), TLD under the cover (number of procedures performed in period - 119).

to the eye lens and the dose to the scalp were observed. The percentage difference between $\mathrm{Hp}(0.07)$ and $\mathrm{Hp}(3)$ in this case was $2.64 \%$, compared to $7.84 \%$ in the first period. The dose value for the eye lens in the analyzed case decreased from $4.7 \mathrm{mSv}$ per quarter to $2.95 \mathrm{mSv}$ per quarter and from $5.10 \mathrm{mSv}$ per quarter to $3.03 \mathrm{mSv}$ per quarter for the scalp. The differences between the dose to the scalp and the lens in cases where safety glasses partially covered the eye dosimeter ranged from $10 \%$ to $20 \%$. The maximum value of this difference, $63 \%$, was observed for the case in which the ocular dosimeter was completely covered with protective glasses.

The group of nurses showed the most reproducible pattern of exposure to ionizing radiation and its as- 
sessment (no additional individual shields in the head area, constant distance from the radiation source, 100\% frequency of wearing TLD dosimeters). Based on the scatterplots and the correlation matrix, a linear dependence of the dose equivalents $\mathrm{Hp}(3)$ and $\mathrm{Hp}(0.07)$ was observed with respect to the number of procedures, with the total value of dosimetry quantities indicated by the $X$-ray units, the total number of acquisitions and the total time of fluoroscopy. The study sample showed an average correlation (correlation coefficients from 0.5 to 0.7 ) between the dose for the eyes and the skin on the head and dosimetry quantities (exception $\mathrm{Hp}(3)$ and $\mathrm{K}_{\text {air,ref }}$ 0.4), which was statistically significant only for $\mathrm{Hp}(0.07)$ and KAP (correlation coefficient above 0.7 showed high correlation). The correlation between the dose for the eyes and the skin on the head and the number of procedures was high for obvious reasons, while that for the total fluoroscopy time and total number of acquisition images was average.

\section{Discussion}

The conducted measurements clearly show that in the case of not using appropriate individual eye protection (protective glasses, headgear), despite the use of ceiling protective shields, the dose equivalent value for the eye lens is close to the dose limit value of $20 \mathrm{mSv} / \mathrm{year}$. Estimated annual dose equivalents exceeded $15 \mathrm{mSv} /$ year in several cases, which means that, according to the legal regulations currently in force in our country, these employees should be classified as being in category $A$ of exposure to ionizing radiation. For the group of nurses, these values were lower, which is undoubtedly associated with the greater distance from the patient constituting the source of scattered radiation (approximately $1 \mathrm{~m}$ from the workstation of the assistant nurse, and $0.5 \mathrm{~m}$ in the case of the operator) and an additional cover consisting of the operator's body and individual anti-radiation cover. Similar results were obtained by Krisanachind et al. in a study conducted in Thailand (2015-2016). In this study, the dose equivalents for eye lenses exceeding the value of $20 \mathrm{mSv}$ per year were also exceeded in the case of not wearing protective glasses [11]. In a study conducted in a similar period by Haga et al. [12] for a group of personnel performing procedures in the field of invasive cardiology, the annual equivalent dose for the eye lenses of operators was also exceeded in the event of failure to use appropriate shields, and no instance of exceeding the dose threshold was noted for any of the nurses.

An alternative to protective glasses is headgear which additionally covers part of the face (Figure 1), thus limiting the part of scattered radiation coming from these areas and reaching the eye lens. It is worth emphasizing that the radiological thickness of the headgear used is $0.1 \mathrm{~mm}$ eq. $\mathrm{Pb}$ (in the range $50-120 \mathrm{kV}$, according to the data of the equipment manufacturer). The measurements show that the value of the dose equivalent to the eye lens in the measurements using the headgear decreased by $37.2 \%$ compared to the results of the measurements in which the ocular dosimeter was placed outside the protective glasses. It is worth noting that the headgear was worn in only two-thirds of the second measurement period; hence, it can be concluded that the use of a headgear throughout the entire measurement period can further reduce scattered radiation by about $19 \%$. The results also show that the use of protective headgear reduces the dose value on the scalp; thus, the use of protective caps seems rather unwarranted, especially given that a significant part of the scattered radiation reaches the upper part of the operator's body from below (the patient's body), as indicated in the introduction to this paper.

There have been reports suggesting a relationship between chronic occupational exposure to ionizing radiation and the incidence of brain tumors in physicians working with surgical X-ray units, which was mentioned in the introduction to this paper. These reports suggest a relationship between the occurrence of neoplasms in the left side of the brain, i.e. the side which is more exposed to scattered radiation in most cases $[7,8]$. It is worth emphasizing that there are certain types of neoplasms that occur more frequently in this area in the entire population [13]. This topic is also discussed in ICRP report No. 139, which shows that these reports are not supported by scientific evidence [2]. However, in order to refer to these reports, and to determine the degree of X-ray exposure of our employees, we carried out measurements of dose equivalents on the scalps of personnel performing radiological procedures. On the basis of the results obtained, we attempted to estimate the dose on the staff member's brain in the area of the scattered beam entry (in the analyzed scenario, the brain is not uniformly irradiated). The estimates show that the mean value of brain doses for cardiologists was $4.32 \mathrm{mSv}$ per year and $1.49 \mathrm{mSv}$ per year for the group of nurses. These values fluctuate around $1 \mathrm{mSv}$ per quarter. In a large epidemiological study (over 110,000 electroradiology technicians) carried out in the period of 1983-2012, the cumulative mean dose absorbed in the brain was estimated at $12 \mathrm{mGy}$ (ranging from 0 to $290 \mathrm{mGy}$ ) [14]. This study did not show a relationship between mortality caused by brain tumors and occupational exposure to ionizing radiation. In this study, the average absorbed dose was estimated based on the reconstruction of dosimetric data and other factors affecting the exposure level (e.g. use of radiological protection procedures, X-ray equipment, exposure time). The dose values estimated in the above work and in our research are at a similar level (slight differences are probably due to the distance to the workplace, and the fact that, in our study, dosage to the brain 
was estimated in the area of the scattered beam entry, not throughout the brain).

In our study, the mean value of the dose equivalent for the eye lens for a single procedure was also determined. Our results confirm the observations made so far. ICRP report No. 139 includes information about studies in which the equivalent dose for the eye lens was determined at the level of $23 \mu \mathrm{Sv}$ per procedure [2] for 144 interventional procedures (mainly cardiological). The literature also provides equivalent dose values for the lens of the eye in the range of 10 to $100 \mu$ Sv per procedure [15]. The wide range of these values depends primarily on the type of procedure, fluoroscopy time, $X$-ray equipment operating parameters, and the use of individual covers in the form of protective glasses.

One of the most important factors in protecting the operator's head and neck is the use of a ceiling protective shield (most often $0.5-1.0 \mathrm{~mm} \mathrm{~Pb}$ ) which reduces the dose received in these areas by two to 10 times (this value varies depending on the correct setup of the ceiling protective shields) [2], and the eye dose by a factor of 19 [1]. This cover can be additionally supported from the bottom by a curtain, which also covers the operator's hand [16]. According to studies conducted in clinical intervention procedures as well as simulations using a phantom, the dose reducing factor (DRF) of ceiling protective shields is 0.7-19. Higher DRF values were achieved during studies in which ceiling protective shields were precisely positioned [2]. Properly positioned ceiling protective shields should be between the patient's irradiated area and the operator. In interventional procedures, in which a variable angle of the primary beam is used (variable C-arm angulation), and the operating table moves, proper placement of the ceiling protective shields requires a frequent change in their position, which can be quite burdensome. Improper use can therefore reduce their effectiveness. The protection of the heads of personnel working with X-ray units is also provided by headgear and protective glasses. Most of the scattered radiation reaches the upper body of the operator and assisting personnel from below. For most of the procedure, the surgeon looks towards the monitors presenting the fluoroscopic and acquisition image; as a result, his eyes are not directed towards the source of scattered radiation. In such a situation, the radiation can reach the eyes through the gap between the glasses and the face; it is such a situation that generates the largest proportion of scattered radiation reaching the eyes. Correct fit and the lead reinforcement of the frames and side sections are therefore very important. As mentioned above, most of the scattered radiation reaches the upper part of the body from below, which is why the use of protective caps is unwarranted.

Finally, it is worth emphasizing the basic problem, which is also indicated in the literature. In the assess- ment of occupational exposure to ionizing radiation, this issue is the lack or improper use of individual dosimetry, which makes it difficult to assess the exposure of personnel. According to data from 2014, obtained as a result of a study conducted among medical personnel by the IAEA (ISEMIR), 76\% of surgical cardiologists stated that they always wear a personal dosimeter, and $45 \%$ of them used a double dosimetry system (one over an individual anti-radiation shield, and the second below it) [2]. The authors argue, however, that due to the subjective nature of the assessment, these data may be overestimated. According to the results obtained in our study, as well as the information contained in the questionnaires completed by the staff, 28 people stated that they did not wear personal dosimeters at all. The lack or improper use of individual dosimetry significantly inhibits the assessment of the degree of exposure of personnel, and thus the implementation of appropriate solutions aimed at risk minimization.

The basic limitations of the study include the lack of a sufficient number of measurements among the full group of medical personnel participating in intervention procedures (a lack of or limited frequency of wearing individual dosimeters). In this research, the exposure assessment in an annual system was performed based on estimated values from quarterly measurements. For a more accurate assessment, measurements over a full calendar year should be considered.

\section{Conclusions}

Dose equivalents for the lenses of the eyes obtained by personnel performing cardiology procedures may be close to or exceed the current dose limits $(20 \mathrm{mSv}$ per year), especially in the absence of additional shields for head areas. The use of only covers in the form of ceiling protective shields is insufficient. The mean value of brain doses for cardiologists was $4.32 \mathrm{mSv}$ per year and $1.49 \mathrm{mSv}$ per year for the group of nurses. These values fluctuate around $1 \mathrm{mSv}$ per quarter.

Dose equivalents received by nursing staff are lower than dose equivalents received by operators.

\section{Acknowledgments}

This research was funded by the statutory funds of the Medical University of Silesia.

\section{Conflict of interest}

The authors declare no conflict of interest.

\section{References}

1. Hirshfeld JWJ, Ferrari VA, Bengel FM, et al. 2018 ACC/HRS/NAS$\mathrm{Cl} / \mathrm{SCAl} / \mathrm{SCCT}$ Expert Consensus Document on Optimal Use of Ionizing Radiation in Cardiovascular Imaging: Best Practices for Safety and Effectiveness: A Report of the American College of 
Cardiology Task Force on Expert Consensus Decision Pat. J Am Coll Cardiol 2018; 71: e283-351.

2. López PO, Dauer LT, Loose R, et al. ICRP Publication 139: Occupational Radiological Protection in Interventional Procedures. Ann ICRP 2018; 47: 1-118.

3. McCabe BP, Speidel MA, Pike TL, Van Lysel MS. Calibration of GafChromic XR-RV3 radiochromic film for skin dose measurement using standardized $\mathrm{x}$-ray spectra and a commercial flatbed scanner. Med Phys 2011; 38: 1919-30.

4. International Commission on Radiological Protection. Statement on Tissue Reactions. Icrp 4825-3093-1464 2011; 2011: 21-2.

5. The 2007 Recommendations of the International Commission on Radiological Protection. ICRP publication 103. Ann ICRP 2007; 37: 1-332.

6. Council Directive 2013/59//EURATOM of 5 December 2013.

7. Roguin A, Goldstein J, Bar O. Brain tumours among interventional cardiologists: a cause for alarm? Report of four new cases from two cities and a review of the literature. Eurolntervention 2012; 7: 1081-6.

8. Roguin A, Goldstein J, Bar O, Goldstein JA. Brain and neck tumors among physicians performing interventional procedures. Am J Cardiol 2013; 111: 1368-72.

9. Schueler BA, Vrieze TJ, Bjarnason H, Stanson AW. An investigation of operator exposure in interventional radiology. Radiographics 2006; 26: 1533-41.

10. Jones AK, Balter S, Rauch P, Wagner LK. Medical imaging using ionizing radiation: optimization of dose and image quality in fluoroscopy. Med Phys 2014; 41: 14301.

11. Krisanachinda A, Srimahachota S, Matsubara K. The current status of eye lens dose measurement in interventional cardiology personnel in Thailand. Radiol Phys Technol 2017; 10: 142-7.

12. Haga Y, Chida K, Kaga Y, et al. Occupational eye dose in interventional cardiology procedures. Sci Rep 2017; 7: 569.

13. Ellingson BM, Lai A, Harris RJ, et al. Probabilistic radiographic atlas of glioblastoma phenotypes. AJNR Am J Neuroradiol 2013; 34: 533-40.

14. Kitahara CM, Linet MS, Balter S, et al. Occupational radiation exposure and deaths from malignant intracranial neoplasms of the brain and CNS in U.S. Radiologic Technologists, 1983-2012. AJR Am J Roentgenol 2017; 208: 1278-84.

15. Thrapsanioti Z, Askounis P, Datseris I, et al. Eye lens radiation exposure in greek interventional cardiology personnel. Phys Medica 2016; 32: 291.

16. Vanhavere F, Carinou E, Gualdrini G, et al. The ORAMED Project: Optimisation of Radiation Protection for Medical Staff. In: World Congress on Medical Physics and Biomedical Engineering September 7-12, 2009 Munich, Germany. Dössel O, Schlegel WC (eds.). Springer Berlin, Heidelberg 2009; 470-3. 